\title{
Nihonella gen. nov., a new troglophilic genus of dwarf spiders from Japan with a discussion on its phylogenetic position within the subfamily Erigoninae (Araneae, Linyphiidae)
}

\author{
Francesco BALLARIN ${ }^{1, *} \&$ Takeshi YAMASAKI ${ }^{2}$ \\ ${ }^{1}$ Systematic Zoology Laboratory, Department of Biological Sciences, Tokyo Metropolitan University, \\ 1-1 Minami-Osawa, Hachioji-shi, 192-0397, Tokyo, Japan. \\ ${ }^{1}$ Department of Zoology, Museo Civico di Storia Naturale di Verona, Lungadige Porta Vittoria 9, \\ I-37129, Verona, Italy. \\ ${ }^{2}$ Institute of Nature and Environmental Sciences, University of Hyogo/Museum of Nature and Human \\ Activities, Hyogo, Yayoigaoka 6, Sanda-shi, 669-1546, Hyogo, Japan. \\ *Corresponding author: ballarin.francesco@gmail.com \\ 2Email: yamasaki@hitohaku.jp \\ 1 (1) https://orcid.org/0000-0003-1417-2519 \\ $2 \odot$ https://orcid.org/0000-0002-2419-188X \\ ${ }^{1}$ urn:1sid:zoobank.org:author:54F6F9C7-0385-48D4-AB09-52692BD05B53 \\ ${ }^{2}$ urn:1sid:zoobank.org:author:804886B5-C951-490C-95C4-D2CA7F4F94D7
}

\begin{abstract}
A new monospecific genus belonging to the family Linyphiidae Blackwell, 1859, Nihonella gen. nov., is described using an integrative taxonomic approach based on the species $N$. chika gen. et sp. nov. The new genus is endemic to Western Honshu, Japan, and it shows distinctive genitalic and somatic characters of other genera of the subfamily Erigoninae Emerton, 1882. Nihonella gen. nov. is found only in the twilight and transition zones of caves in Okayama and Nara Prefectures. The phylogenetic position of Nihonella gen. nov. within the subfamily Erigoninae, and its relationship as a sister clade of the species of the group of Savignia Blackwell, 1833 (sensu Millidge 1977), is discussed on the basis of both, morphological and molecular evidence.
\end{abstract}

Keywords. Caves, endemism, new species, phylogeny, subterranean environment.

Ballarin F. \& Yamasaki T. 2021. Nihonella gen. nov., a new troglophilic genus of dwarf spiders from Japan with a discussion on its phylogenetic position within the subfamily Erigoninae (Araneae, Linyphiidae). European Journal of Taxonomy 733: 1-18. https://doi.org/10.5852/ejt.2021.733.1215

\section{Introduction}

Within the order Araneae, the spider family Linyphiidae Blackwall, 1859 is the second largest by number of species: currently 4638 species are known in 617 genera, with a worldwide distribution (World Spider Catalog 2020). Among them, the subfamily Erigoninae Emerton, 1882 is undoubtedly the most diverse 
and species-rich (Tanasevitch 2020). At middle latitudes, these tiny spiders live in a wide range of habitats including forest leaf litter, empty spaces between rocks, and caves, where they build small sheet-webs. In Japan, 293 linyphiid species belonging to 109 genera are currently recorded (Tanikawa 2020). Although some Japanese species can colonize the entrances of caves or other semi-subterranean environments, the hypogean environment supports only a few species (Ono et al. 2009).

While collecting in caves in Central and Western Honshu, Japan, we found several specimens of spiders belonging to different families, including some Linyphiidae. A detailed morphological analysis of the collected material led to the discovery of an unknown linyphiid species belonging to the subfamily Erigoninae. The peculiar somatic characters, as well as the shape of the epigyne and male palp, excluded this species from the currently known genera. Thus, herein we describe this spider as a new species, and we establish a new genus on the basis of morphological and molecular evidence. To support this claim and to clarify the phylogenetic position of the new genus within the subfamily Erigoninae, we conducted a multi-locus phylogenetic analysis, the results of which are herein discussed.

\section{Material and methods}

\section{Taxonomy}

Specimens were collected inside caves in Okayama and Nara Prefectures (Western Honshu Island, Japan) and immediately preserved in $99 \%$ ethanol for morphological and molecular studies. Samples were studied at the Systematic Zoology Laboratory, Department of Biological Sciences, Tokyo Metropolitan University, Japan (TMU). A Nikon SMZ1270 stereo microscope and a Nikon Optiphot 2 microscope were used to observe habitus and genitalia of the specimens, and to take measurements. Photographs were taken using a Canon EOS60D digital camera mounted on the microscopes. Final images were merged with Helicon Focus 7 image stacking software. Additional scanning electron micrographs were taken using a Jeol JSM-6510LV scanning electron microscope at TMU. The male left palp was drawn and photographed. Epigyne was dissected using a sharp scalpel and cleared with lactic acid to show the inner structures. All measurements are reported in millimeters, leg measurements are given as total length (femur, patella, tibia, metatarsus, tarsus). The specified chaetotaxy (= tibial spine formula) refers to the number of dorsal spines on tibiae I-IV. All vouchers used in this study are preserved in the National Museum of Nature and Science, Tokyo, Japan (NMST).

\section{Institutional abbreviations}

NSMT $=$ National Museum of Nature and Science, Tokyo, Japan

TMU $=$ Tokyo Metropolitan University, Japan

\section{Abbreviations used in the text and figures}

$\mathrm{AW}=$ anterior wall of epigyne
$\mathrm{C}=$ cymbium
$\mathrm{CD}=$ copulatory duct
$\mathrm{CO}=$ copulatory opening
$\mathrm{D}=$ duct
$\mathrm{DSA}=$ distal suprategular apophysis
$\mathrm{E}=$ embolus
$\mathrm{LW}=$ lateral walls of epigyne
$\mathrm{MM}=$ median membrane
$\mathrm{PC}=$ paracymbium
$\mathrm{PP}=$ posterior median plate
$\mathrm{PT}=$ protegulum
$\mathrm{PTA}=$ prolateral tibial apophysis




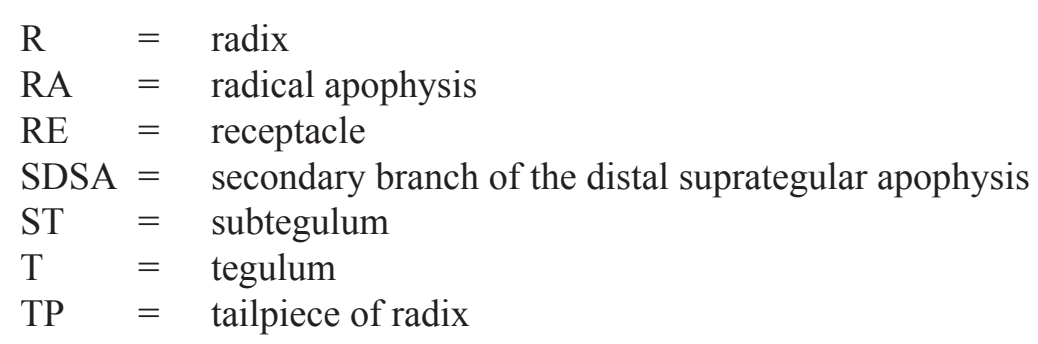

\section{Molecular analysis}

The complete genomic DNA was extracted from four legs of each sample using a Qiagen DNeasy Blood \& Tissue Kit, following the standard protocol suggested by the manufacturer. Extraction and Polymerase Chain Reaction amplification (PCR) of the samples were performed at TMU. Genomic DNA from voucher specimens was stored in a freezer at $-20^{\circ} \mathrm{C}$ at the same institute. Five gene fragments were amplified using standard primers: cytochrome c oxidase subunit I(COI), 16SrRNA(16S), 18SrRNA(18S), 28SrRNA (28S), and histone 3 (H3). PCR amplifications were performed using a SimpliAmp Thermal Cycler (Thermo Fisher Scientific, USA) with a final volume of $11 \mu 1$. All primers and protocols used in this study follow Arnedo et al. (2009). In addition, the following primers were also used to amplify the first segment of 18S: 18S-1F (forward) TACCTGGTTGATCCTGCCAGTAG (Giribet et al. 1996) and 18S-SSU (reverse) GTGGTGCCCTTCCGTCAATT (Balczun et al. 2005). Purified PCR products were submitted and sequenced by Eurofins Genomics Company, Tokyo branch. Sequences of other linyphiid spiders used in the analysis were obtained from GenBank (https://www.ncbi.nlm.nih.gov/genbank/). In order to clarify the phylogenetic position of the new genus herein described, we reconstructed a simplified phylogenetic tree of Linyphiidae, including representative species of the five main subfamilies distributed in the Palearctic region: Stemonyphantinae (Wunderlich, 1986), Linyphiinae (Blackwell, 1859), Micronetinae (Hull, 1920), Ipainae Saaristo, 2007, and Erigoninae. A preliminary morphological study of our samples suggested that the new genus was closely related to the species of the Savignia group sensu Millidge, 1977. Thus, we focused the sampling especially on the Erigoninae subfamily, including distal Erigoninae, genera located in early branches, and species belonging to the Savignia group. Pimoa rupicola (Simon, 1884) from the family Pimoidae Simon, 1884 was preferentially selected as an outgroup to root the tree, due to the close relationship between Pimoidae and Linyphiidae (Wheeler et al. 2017; Fernandez et al. 2018). Fifty-eight taxa composed the final dataset. The complete list of sequences and related GenBank identification codes are reported in Table 1.

Final sequences were edited using Bioedit ver. 7.0.5 (Hall 1999) and aligned using the online version of MAFFT ver. 7.450 (Katoh et al. 2019) under the G-INS-I (COI, 18S, H3) and Q-INS-i (16S, 28S) algorithms. Protein coding genes (COI, H3) were translated to proteins using MEGA X ver. 10.0.5 (Kumar et al. 2018) to check for potential errors. A Bayesian Inference analysis was performed using the online version of MrBayes ver. 3.2.7 (Ronquist et al. 2012) available on the CIPRES Science Gateway ver. 3.3 (Miller et al. 2010). Two independent runs of four Markov Chain Monte Carlo algorithms were run for 20 million generations, sampled every 2000 generations with a burn-in of $25 \%$. We used the partition scheme and substitution model suggested by PartitionFinder 2 ver. 2.1.1 (Lanfear et al. 2016) under a corrected Akaike information criterion (AICc). Tracer ver. 1.7.1 (Rambaut et al. 2018) was used to establish that the effective sample size was $>200$ for all the parameters. The concatenated sequences in the final dataset were formed by a total of 3983 nucleotides divided as follows: $\mathrm{COI}=672,16 \mathrm{~S}=432$, $18 \mathrm{~S}=1704,28 \mathrm{~S}=848, \mathrm{H} 3=327$.

In order to compare the genetic distance between the new genus and the main components of the Savignia group, partial fragments of the COI barcodes of nine species within the group were found on GenBank (see Table 1). The GenBank sequences were compared with the new genus sequences using an 
Table 1. List of the species, gene fragments and related GenBank accession codes used to reconstruct the phylogenetic tree and in P-distance analyses. The new genus is highlighted in red color, asterisks refer to new sequences.

\begin{tabular}{|c|c|c|c|c|c|c|}
\hline Species & COI & $16 S$ & $18 \mathrm{~S}$ & $28 \mathrm{~S}$ & H3 & Notes \\
\hline Agyneta ramosa & FJ838648 & FJ838670 & FJ838694 & FJ838717 & FJ838740 & \\
\hline Araeoncus crassipalpis & KY270223 & & & & & $\begin{array}{l}\text { only for } \\
\text { P-distance }\end{array}$ \\
\hline Asthenargus sp. & missing & missing & GU338493 & GU338561 & missing & \\
\hline Bathyphantes gracilis & KM836935 & KT003103 & GU338464 & FJ838719 & FJ838742 & \\
\hline Bolyphantes alticeps & KY268546 & AY078660 & AY078667 & AY078678 & AY078700 & \\
\hline Centromerus trilobus & GU338656 & GU338599 & GU338468 & GU338571 & KT002817 & \\
\hline Ceratinopsis setoensis & JN817121 & JN816488 & JN816709 & JN816919 & missing & \\
\hline Dicymbium sinofacetum & EF128167 & GU338614 & GU338487 & GU338546 & missing & \\
\hline Dicymbium tibiale & KY268930 & KT003114 & KT002923 & KT003021 & KT002824 & $\begin{array}{l}\text { also for } \\
\text { P-distance }\end{array}$ \\
\hline Diplocentria bidentata & KM840840 & GU338629 & GU338494 & GU338542 & missing & \\
\hline Diplocephalus cristatus & GU338696 & GU338637 & GU338490 & missing & missing & $\begin{array}{c}\text { also for } \\
\text { P-distance }\end{array}$ \\
\hline Diplostyla concolor & GU682473 & GU338639 & GU338467 & GU338585 & FJ838743 & \\
\hline Doenitzius pruvus & JN817116 & GU338632 & GU338474 & KT003023 & KT002826 & \\
\hline Drapetisca socialis & KY268428 & FJ838674 & FJ838698 & FJ838721 & FJ838744 & \\
\hline Erigone edentata & GU338686 & missing & GU338486 & GU338540 & missing & \\
\hline Erigone prominens & EF128171 & missing & GU338498 & GU338539 & КT002828 & \\
\hline Erigonella ignobilis & KX039173 & & & & & $\begin{array}{c}\text { only for } \\
\text { P-distance }\end{array}$ \\
\hline Eskovina clava & JN817122 & JN816489 & JN816710 & JN816920 & missing & \\
\hline Floronia bucculenta & KY270282 & FJ838676 & KT002928 & $\begin{aligned} & \text { FJ838723 } \\
&+ \text { KT003026 }\end{aligned}$ & FJ838746 & \\
\hline Frontinella communis & KY017766 & KY015924 & KY016500 & KY017142 & KY018271 & \\
\hline Glyphesis servulus & KY269551 & & & & & $\begin{array}{c}\text { only for } \\
\text { P-distance }\end{array}$ \\
\hline Gnathonarium dentatum & JN306340 & GU338593 & GU338477 & GU338548 & missing & \\
\hline Gonatium rubellum & FJ838656 & FJ838679 & FJ838703 & FJ838726 & FJ838749 & \\
\hline Gonatium rubens & KY269351 & KT003120 & KT002930 & KT003028 & KT002831 & \\
\hline Grammonota sp. & HQ924393 & missing & GU338491 & missing & missing & \\
\hline Helophora insignis & FJ838658 & FJ838681 & FJ838705 & FJ838728 & FJ838751 & \\
\hline Hylyphantes graminicola & KY270332 & GU338595 & GU338478 & JN816917 & KT002835 & \\
\hline Hylyphantes sp. irellus & GU338668 & GU338618 & GU338481 & GU338549 & missing & \\
\hline Janetschekia monodon & KJ363172 & & & & & $\begin{array}{l}\text { only for } \\
\text { P-distance }\end{array}$ \\
\hline Lepthyphantes sp. & GU338664 & GU338610 & GU338509 & GU338562 & missing & \\
\hline Lepthyphantes minutus & KY270131 & AY078663 & AY078673 & AY078681 & AY078705 & \\
\hline Lin02 Nihonella chika & MW177572* & MW192653* & MW192647* & MW192650* & MW177569* & $\begin{array}{l}\widehat{\partial} \text { from Anatoya- } \\
\text { ma cave }\end{array}$ \\
\hline Lin04 Nihonella chika & MW177573* & MW192654* & MW192648* & MW192651* & MW177570* & $\begin{array}{l}\text { o from Uyama- } \\
\text { do cave, also for } \\
\text { P-distance }\end{array}$ \\
\hline Lin05 Nihonella chika & MW177574* & MW192655* & MW192649* & MW192652* & MW177571* & $\begin{array}{c}\text { f from Komori- } \\
\text { noiwaya cave }\end{array}$ \\
\hline
\end{tabular}


BALLARIN F. \& YAMASAKI T., Nihonella, a new linyphiid genus from Japan

Table 1. Continued.

\begin{tabular}{|c|c|c|c|c|c|c|}
\hline Species & COI & $16 S$ & $18 \mathrm{~S}$ & $28 \mathrm{~S}$ & H3 & Notes \\
\hline Linyphia triangularis & AY078693 & AY078664 & $\begin{array}{r}\text { EU003390 } \\
+ \text { AY078668 }\end{array}$ & $\begin{array}{c}\text { EU003410 } \\
+ \text { EU153170 }\end{array}$ & AY078702 & \\
\hline Meioneta nigra & GU338662 & GU338608 & GU338504 & GU338577 & missing & \\
\hline Micrargus herbigradus & KY270158 & KT003135 & KT002947 & KT003042 & KT002848 & \\
\hline Microctenonyx subitaneus & KX039262 & & & & & $\begin{array}{l}\text { only for } \\
\text { P-distance }\end{array}$ \\
\hline Microneta viaria & FJ838661 & FJ838684 & GU338502 & GU338537 & FJ838754 & \\
\hline Moebelia rectangula & missing & GU338591 & GU338485 & GU338557 & missing & \\
\hline Nematogmus sanguinolentus & KX039278 & GU338635 & GU338489 & GU338544 & missing & \\
\hline Neriene macella & MG201053 & MG200522 & MG200699 & MG200873 & MG201230 & \\
\hline Neriene radiata & KM839120 & KY467286 & GU338463 & JN816906 & AY078709 & \\
\hline Nippononeta kantonis & GU338693 & GU338634 & GU338471 & GU338530 & missing & \\
\hline Nippononeta sp. & GU338657 & GU338602 & GU338520 & GU338531 & missing & \\
\hline Oedothorax apicatus & FJ838664 & FJ838687 & FJ838711 & $\begin{array}{c}\text { FJ838734 } \\
+ \text { +KT003057 }\end{array}$ & FJ838757 & \\
\hline Ostearius melanopygius & KX537231 & FJ838688 & FJ838712 & FJ838735 & FJ838758 & \\
\hline Paikiniana sp. & GU338647 & GU338617 & GU338495 & GU338555 & missing & \\
\hline Parameioneta bilobata & GU338660 & GU338605 & GU338503 & GU338533 & missing & \\
\hline Parasisis sp. & GU338650 & GU338592 & GU338500 & GU338534 & missing & \\
\hline Pimoa rupicola & MG201051 & MG200518 & MG200697 & MG200876 & MG201228 & \\
\hline Porrhomma sp. & GU338661 & GU338607 & GU338466 & GU338584 & missing & \\
\hline Saloca diceros & KY270378 & & & & & $\begin{array}{c}\text { only for } \\
\text { P-distance }\end{array}$ \\
\hline Savignia sp. 1 & KT002778 & KT003165 & KT002977 & KT003071 & KT002879 & \\
\hline Savignia sp. 2 & KT002779 & KT003166 & KT002978 & KT003072 & KT002880 & $\begin{array}{c}\text { also for } \\
\text { P-distance }\end{array}$ \\
\hline Sisicottus montanus & GU338673 & GU338625 & GU338479 & GU338541 & missing & \\
\hline Solenysa mellotteei & KT002781 & KT003168 & KT002980 & KT003076 & КT002884 & \\
\hline Solenysa sp. 14 & GU338667 & GU338603 & GU338507 & GU338528 & missing & \\
\hline Sphecozone bicolor & GU338671 & GU338622 & GU338496 & GU338553 & missing & \\
\hline Stemonyphantes sp. & KY017774 & KY015933 & KY016511 & KY017153 & KY018278 & \\
\hline Tenuiphantes sp. & GU338646 & GU338612 & GU338514 & GU338568 & missing & \\
\hline Tenuiphantes tenuis & KC244266 & FJ838693 & FJ838716 & FJ838739 & FJ838763 & \\
\hline Walckenaeria clavicornis & MN680355 & GU338596 & GU338483 & GU338554 & missing & \\
\hline Walckenaeria keikoae & GU338695 & GU338636 & GU338484 & GU338556 & missing & \\
\hline
\end{tabular}

uncorrected pairwise-distance genetic sequence divergence, run in MEGA X using a bootstrap method with 1000 replications. 


\title{
Results
}

Taxonomy

\author{
Class Arachnida Cuvier, 1812 \\ Order Araneae Clerck, 1757 \\ Family Linyphiidae Blackwall,1859 \\ Subfamily Erigoninae Emerton, 1882 \\ Nihonella gen. nov. \\ urn:lsid:zoobank.org:act:05F43F8A-6FBC-4A95-98FF-56CEFACF73DB
}

Figs 1A-G, 2-4; Table 2

\section{Type species}

Nihonella chika gen. et. sp. nov.

\section{Diagnosis}

The new genus is distinguished from any other genera belonging to the distal Erigoninae clade by the following unique combination of somatic and genitalic characters: Femur I with 1 prolateral spine; Tibia I with 1 dorsal spine; tibial spine formula: 1.1.1.1; male palp with a well-developed distal suprategular apophysis and a hypertrophic 'secondary' DSA (Figs 2A-B, 3A-C, 4A-E) (usually presented in Erigoninae as a simple tooth and protruding form a different side of the DSA); a well-developed and uniquely-shaped prolateral tibial apophysis, the same length as the cymbium and partially covering it (Figs $2 \mathrm{~A}-\mathrm{C}, 3 \mathrm{~A}-\mathrm{B}, \mathrm{D}, 4 \mathrm{E}-\mathrm{F}$ ). The unusual chaetotaxy and unique shape of the epigyne, with anteriorly converging lateral walls and two distinct, flat, ovoid inflations of the copulatory ducts, also distinguishes the female of this genus from females of any other genera in distal Erigoninae.

\section{Etymology}

The generic name is a combination of the word 'Nihon' and the Latin suffix '-ella'. The former refers to the country of Japan where the genus is endemic; the latter is the feminine suffix of '-ellus' commonly used in Latin to form the feminine diminutive of a noun. Name in apposition, feminine in gender.

\section{Species included}

Only the type species Nihonella chika gen. et. sp. nov.

\section{Taxonomic remarks}

The morphology of Nihonella gen. nov. suggests it may be closely related to the species of the Savignia group. However, the presence of numerous differences in genitalia shape and somatic characters does not allow us to include the new genus within this group of species. A close but distinct relationship with the Savignia group is also supported by the molecular analysis (see Fig. 5).

Nihonella gen. nov. male palps have a general morphology similar to those found in some genera of the Savignia group (e.g., Araeoncus Simon, 1884 or Diplocephalus Bertkau, 1883). They share a similar shape in the embolic division: a long, modified palpal tibia, and a well-developed DSA. However, the new genus shows a distinct hypertrophy of the SDSA, which is extremely long and clearly protruding outside the frontal part of the palpal bulb (Figs 2A-B, D, 3A-C, 4A-E). Within the subfamily Erigoninae, some genera belonging to the Savignia group (sensu Millidge 1977) have a large DSA and a tooth-like SDSA (e.g., Alioranus Simon, 1926, Dactylopisthes Simon, 1884, Delorrhipis Simon 1885, Savignia Blackwall, 1833, etc., see Millidge 1977: figs 128, 135-136, 139). However, none of the Savignia group display a SDSA as strongly developed as in Nihonella gen. nov. Females of Nihonella gen. nov. 
have an epigyne with two anteriorly converging lateral walls, which resembles the female genitalia, of most of genera within the Savignia group (e.g., Araeoncus Simon, 1884, Diplocephalus Bertkau, 1883, Erigonella Dahl, 1901, Savignia Blackwall, 1833, etc.). Nevertheless, both males and females
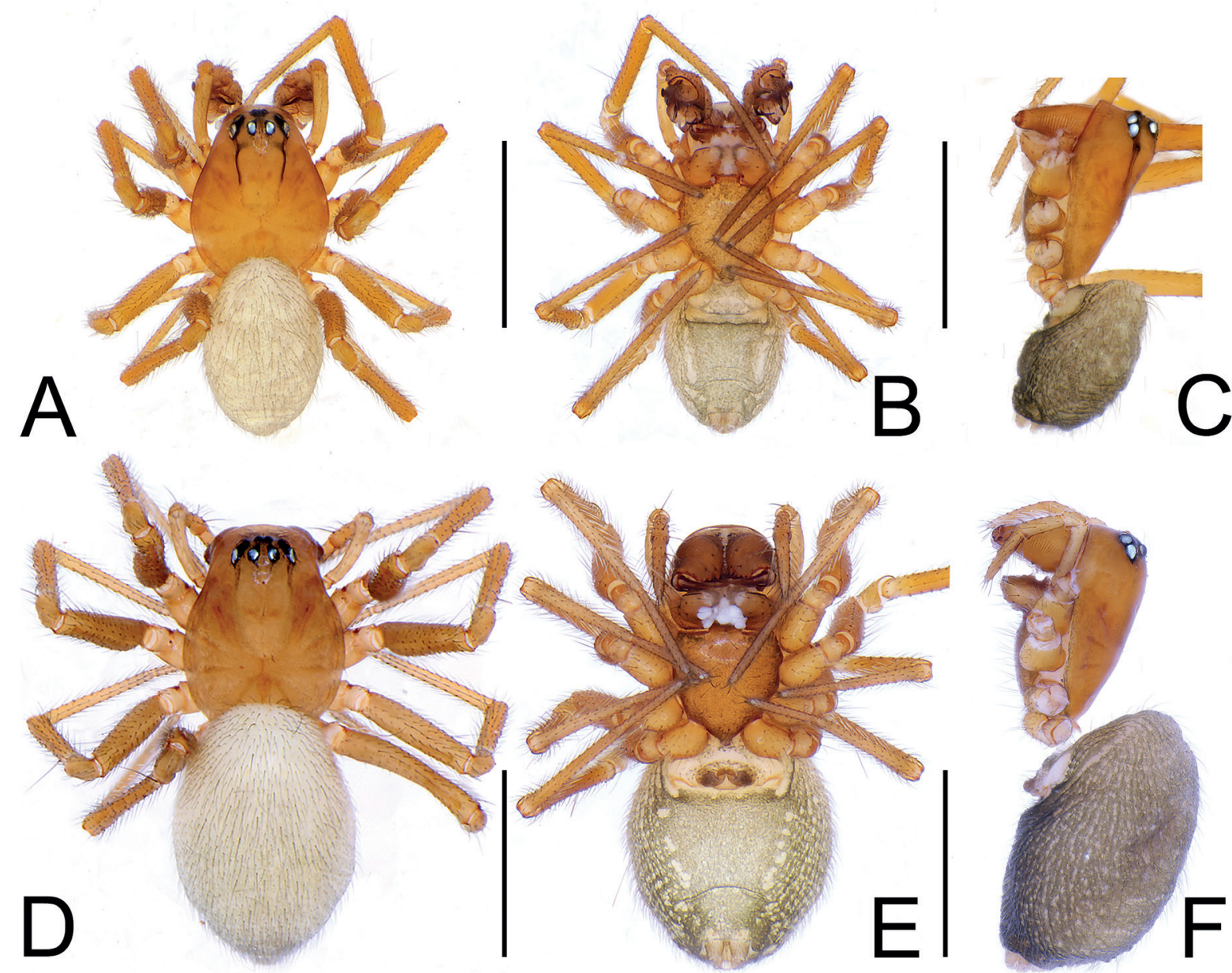
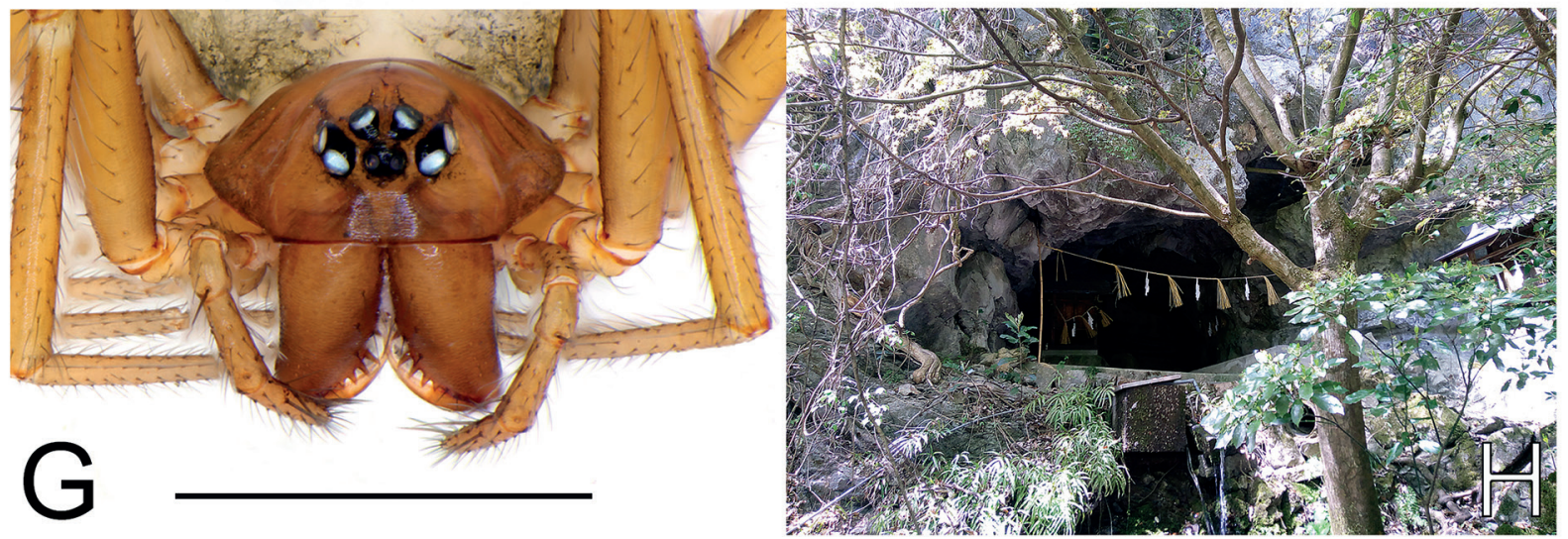

Fig. 1. Habitus and habitat of Nihonella chika gen. et. sp. nov. A. §, holotype (NSMT-Ar 20909), habitus, dorsal view. B. Ditto, ventral view. C. Ditto, lateral view. D. क, paratype (NSMT-Ar 20910), habitus, dorsal view. E. Ditto, ventral view. F. Ditto, lateral view. G. Ditto, cephalic region, frontal view. H. Entrance of Anatoyama Cave, type locality of the species. Scale bar $=1 \mathrm{~mm}$. 
Table 2. Uncorrected Pairwise-distance between the genus Nihonella gen. nov. (in bold) and the main genera included in the Savignia group based on the barcode COI partial sequence.

\begin{tabular}{|c|c|c|c|c|c|c|c|c|c|}
\hline & Araeoncus & Dicymbium & Diplocephalus & Erigonella & Glyphesis & Janetschekia & Microctenonyx & Saloca & Savignia \\
\hline \multicolumn{10}{|l|}{ Araeoncus } \\
\hline Dicymbium & 0.115 & & & & & & & & \\
\hline Diplocephalus & 0.112 & 0.101 & & & & & & & \\
\hline Erigonella & 0.147 & 0.125 & 0.112 & & & & & & \\
\hline Glyphesis & 0.140 & 0.118 & 0.140 & 0.140 & & & & & \\
\hline Janetschekia & 0.139 & 0.147 & 0.150 & 0.189 & 0.156 & & & & \\
\hline Microctenonyx & 0.156 & 0.147 & 0.144 & 0.155 & 0.143 & 0.143 & & & \\
\hline Saloca & 0.161 & 0.137 & 0.141 & 0.147 & 0.138 & 0.147 & 0.158 & & \\
\hline Savignia & 0.124 & 0.112 & 0.122 & 0.118 & 0.135 & 0.164 & 0.150 & 0.155 & \\
\hline Nihonella & 0.143 & 0.129 & 0.140 & 0.141 & 0.131 & 0.139 & 0.156 & 0.144 & 0.132 \\
\hline
\end{tabular}

of Nihonella gen. nov. have a highly distinctive chaetotaxy which strongly differ from the chaetotaxy usually found in species belonging to the Savignia group (1.1.1.1 vs 2.2.1.1). Although some species included in this group may occasionally have a tibial spine formula of 1.1.1.1, this usually only occurs in males and as a consequence of the reduction of the distal spines in tibia I and II (e.g., Araeoncus crassipes Heimer \& Nentwig, $1991=1.1 .1 .1$, A . humilis $($ Blackwall, 1841) $=0.0 .1 .1$ : Tanasevitch, in litteris). An exception is the genus Microctenonyx Dahl, 1886, the female of which has a tibial spine formula of 1.1.1.1. However, Microctenonyx can be easily distinguished from Nihonella gen. nov. by the large genetic distance between the two genera (see Table 2), and by the shape of the epigyne and male palp (short SDSA, different shape of epigyne and internal ducts, see Figs 2A-H, 3A-D vs Millidge 1977: fig. 140 and Bosmans 2007: figs 111-115).

\section{Distribution}

Endemic to Western Honshu, Japan. Currently known from three caves only (Figs 1H, 6).

Nihonella chika gen. et. sp. nov. urn:1sid:zoobank.org:act:87924F73-CCDB-4872-99A3-20A5A3A4EBE9

Figs 1A-G, 2-4; Table 1

\section{Diagnosis}

Male Nihonella chika gen. et. sp. nov. can easily be distinguished from males of species of the Savignia group by the clearly visible hypertrophic secondary DSA apophysis, long and hooked, which instead is absent or much shorter in species of Savignia and usually straight and tooth-shaped (see Figs 2A-B, D, 3A-C, 4A-E vs Millidge 1977: figs 122-144). Another distinct character of the male Nihonella chika gen. et. sp. nov. is the shape of the prolateral tibial apophysis of the palp: long, partially covering the middle line of the cymbium, and ending with a triangular structure covered with short, stocky spikes (Figs 2A-C, 3A-B, D, 4E-F). Female Nihonella chika gen. et. sp. nov. are easily recognized by the general shape of the epigyne, which has two ovoid, flat inflations of the copulatory ducts where the lateral walls of the epigyne join to each other; further, the anterior wall protrudes slightly (Figs 2E, 3E). The epigyne also has a trapezoidal posterior median plate (Figs $2 \mathrm{~F}-\mathrm{G}, 3 \mathrm{~F}$ ), and a twisted course of the copulatory ducts (Figs 2H, 3G). 

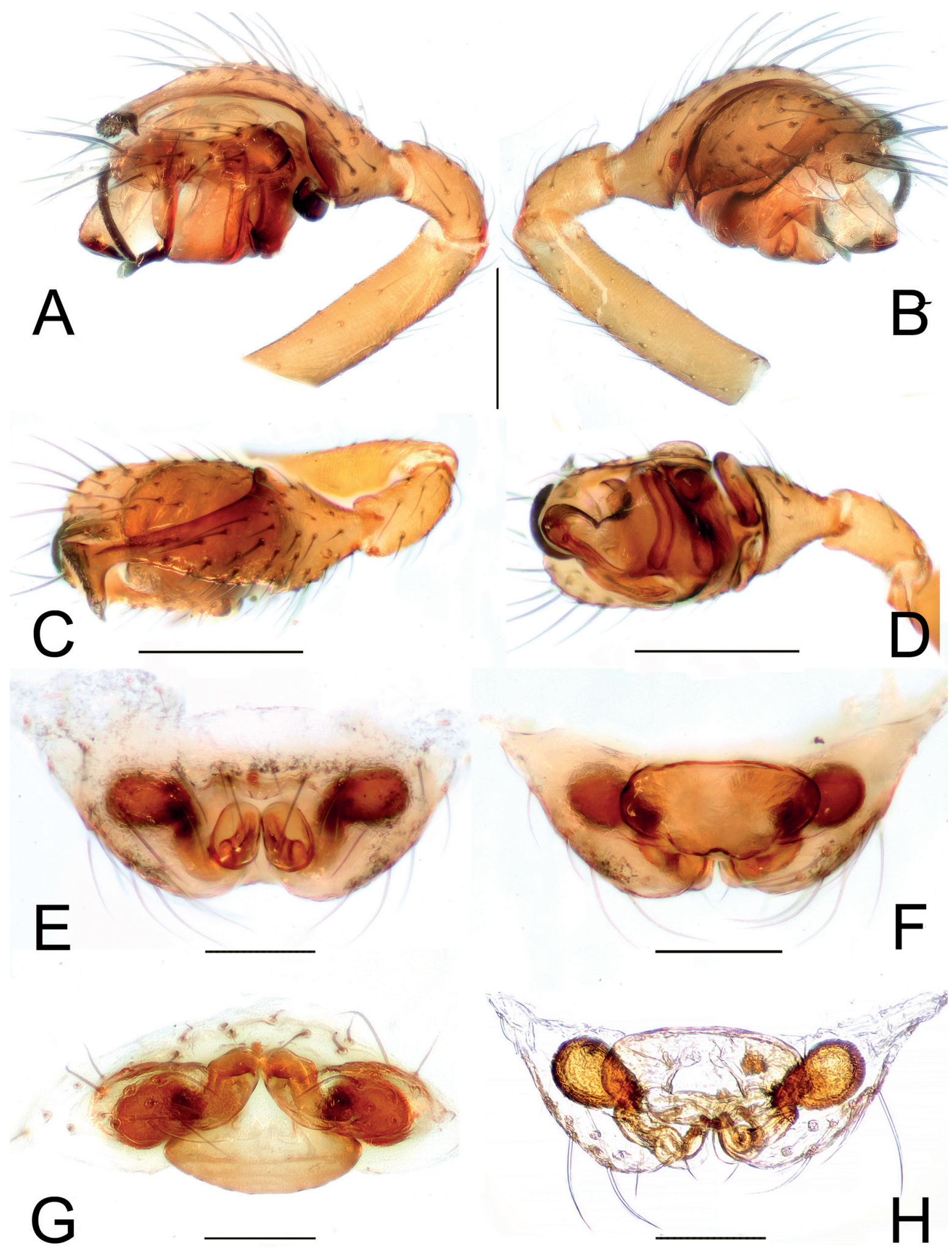

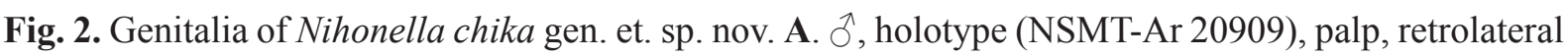
view. B. Ditto, prolateral view. C. Ditto, dorsal view. D. Ditto, ventral view. E. q, paratype (NSMTAr 20910), epigyne, ventral view. F. Ditto, dorsal view. G. Ditto, posterior view. H. Ditto, vulva after being cleared, ventral view. Scale bars: A-D $=0.2 \mathrm{~mm}$; $-\mathrm{H}=0.1 \mathrm{~mm}$. 


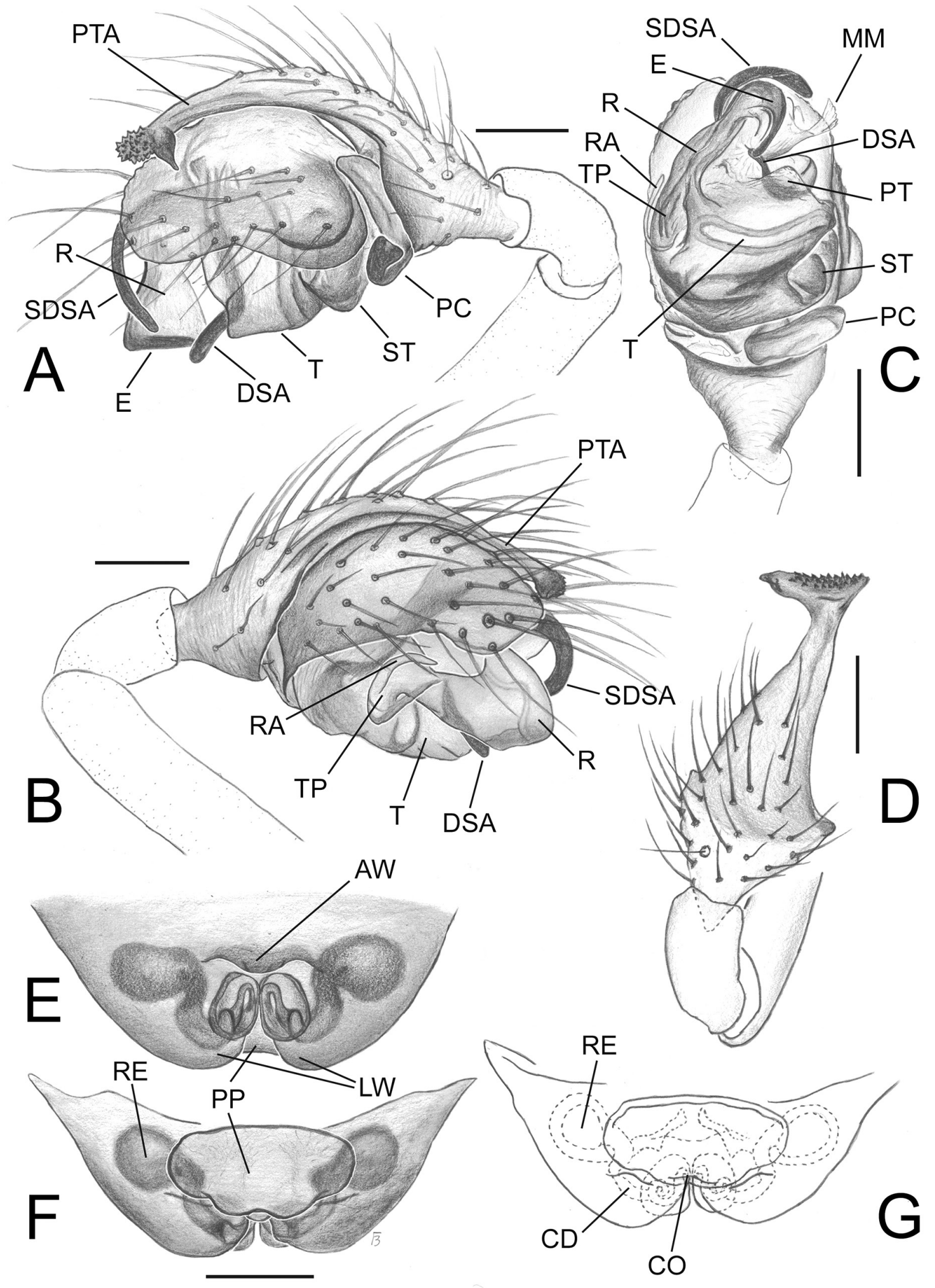

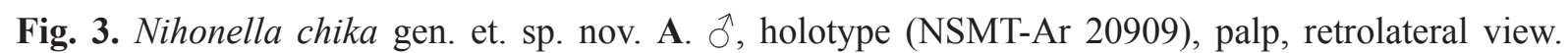
B. Ditto, prolateral view. C. Ditto, ventral view. D. Ditto, palpal tibia, dorsal view. E. $q$, paratype (NSMTAr 20910), epigyne, ventral view. F. Ditto, dorsal view. G. Ditto, vulva, dorsal view. Abbreviations: see Material and methods. Scale bar $=0.1 \mathrm{~mm}$. 


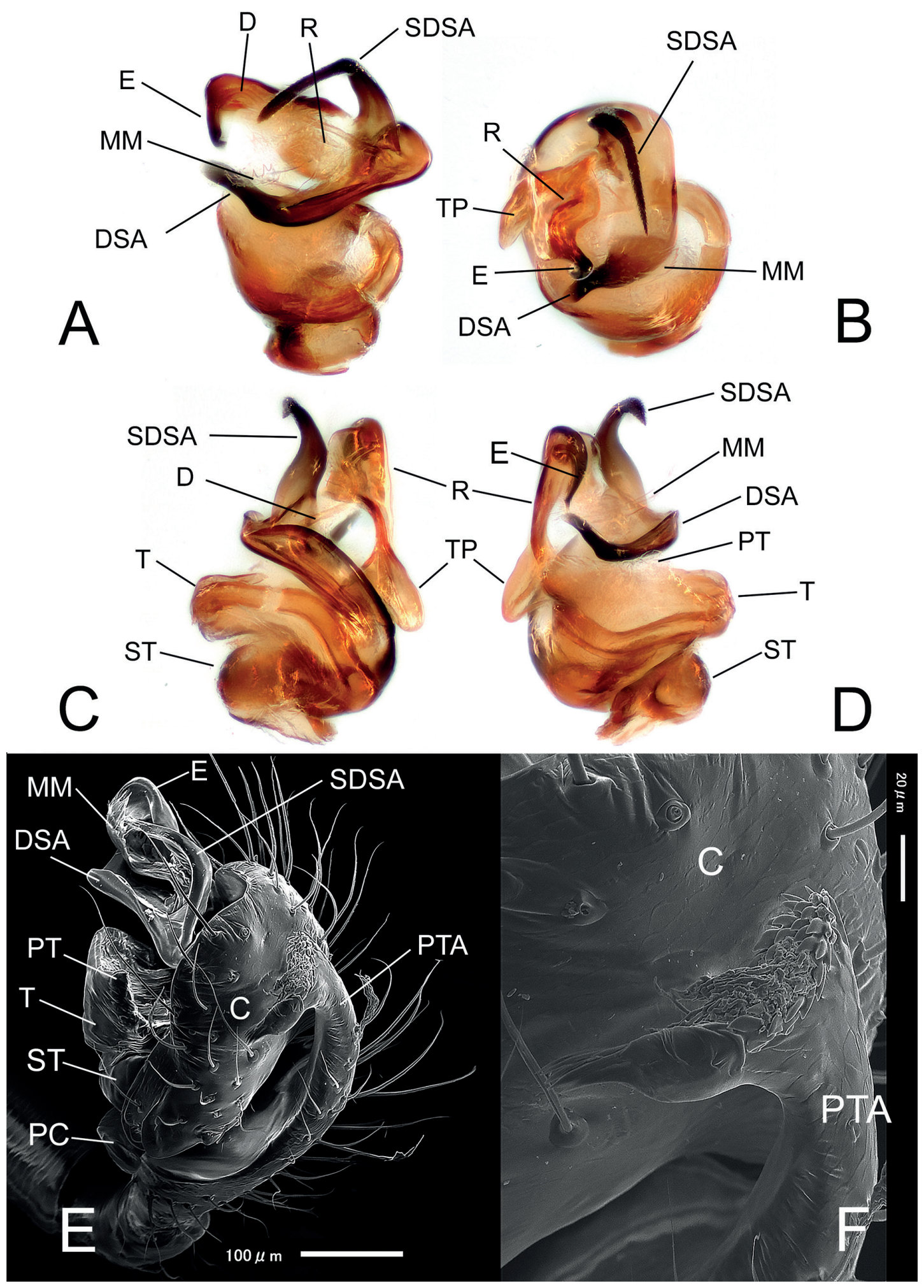

Fig. 4. Embolic division and details of the male palp of Nihonella chika gen. et. sp. nov. A. $\hat{\jmath}$, paratype (NSMT-Ar 20911), embolic division, ventro-retrolateral view. B. Ditto, frontal view. C. Ditto, dorsal view. D. Ditto, ventral view. E. §, paratype (NSMT-Ar 20910), palp under SEM microscope, anteroretrolateral view. F. Ditto, detail of the tip of the prolateral tibial apophysis. Abbreviations: see Material and methods. 


\section{Etymology}

The specific name is derived from the Japanese word 'chika' (地下) meaning 'underground, subterranean' and thus refers to the habitat of the species, but it is also the pronunciation of a feminine given name in the Japanese language. Name in apposition.

\section{Material examined}

\section{Holotype}

JAPAN • đ̄; Honshu Island, Okayama Prefecture, Takahashi-shi, Kawakamichō, Kōyamaichi, Anatoyama Shrine, Anatoyama cave (穴門山洞窟); $34.7440^{\circ} \mathrm{N}, 133.3918^{\circ}$ E; $480 \mathrm{~m}$ a.s.1.; 22 Apr. 2019; Ballarin F. and Yamasaki T. leg.; narrow and long cave behind a Shinto shrine; NSMT-Ar 20909.

\section{Paratypes}

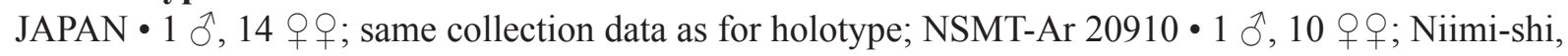
Toyonagauyama, Uyama-do cave (宇山洞); $34.94226^{\circ} \mathrm{N}, 133.57499^{\circ}$ E; 423 m a.s.1.; 21 Apr. 2019; Ballarin F. and Yamasaki T. leg.; large and deep humid cave with a subterranean creek; NSMT-Ar 20911.

\section{Other material}

JAPAN • 1 \&; Honshu Island, Nara Prefecture, Yoshino District, Tenkawa-shi, Dorogawa, Komorinoiwaya cave (蝙蝠の窟); $34.2686^{\circ} \mathrm{N}, 135.8906^{\circ}$ E; 06 Oct. 2019; Ballarin F. and Tanikawa A. leg.; NSMT-Ar 20912.

\section{Description}

Male (holotype)

Habitus. As shown in Fig. 1A-C.

Measurements. Total length: 1.79 , carapace 0.97 long, 0.75 wide.

Prosoma. Carapace, chelicerae, labium, and sternum uniformly light brownish. Head distinctly raised, $\mathrm{AME}=0.04, \mathrm{PME}, \mathrm{ALE}, \mathrm{PLA}=0.06$. Anterior margin of cheliceral groove bearing 5 robust teeth.

Opisthosoma. Opisthosoma uniformly grayish, lacking any pattern, covered with numerous short hairs. Central area of ventral side of opisthosoma slightly lighter.

Legs. Legs uniformly light brownish. Femur I with 1 prolateral spine. Patella I and Tibia I with 1 dorsal spine. Tibial spine formula $=1.1 .1 .1$. One trichobothrium on metatarsi I-III, absent on metatarsus IV. $\mathrm{TmI}=$ approx. 0.55. Leg measurements as follows: Leg I: $3.02(0.84,0.23,0.80,0.71,0.44)$; Leg II: 2.92 (0.81, 0.24, 0.73, 0.66, 0.48); Leg III: 2.44 (0.68, 0.23, 0.58, 0.56, 0.39); Leg IV: 3.15 (0.87, 0.26, $0.82,0.69,0.51)$.

PaLP. As shown in Figs 2A-D, 3A-D, 4E-F. Embolic division as in Fig. 4A-D. Palpal tibia bearing 1 trichobotrium and long prolateral tibial apophysis approximately as long as the cymbium and partially covering it along its median line. PTA triangle-shaped when observed dorsally, ending with triangular spiked structure. Cymbium ovoid when observed dorsally, covering whole bulb with exception of the tip of secondary branch of distal suprategular apophysis. Deep groove along middle line of cymbium, in which rests ventral part of PTA. Paracymbium stumpy and simple, lacking in apophyses. Tailpiece of radix slightly protruding, with well-developed, thin apophysis, hook-like and frontally-oriented. DSA well-developed, hook-like and ending with blunt tip. Secondary branch of distal suprategular apophysis hypertrophic, long and thin, strongly protruding frontally and ventrally, ending with sharp tip. Median membrane transparent and barely visible, protruding retrolaterally. Embolus hook-like, initial trait oriented frontally then ventro-posteriorly, stumpy, ending with blunt end near tip of DSA. 
Female (based on three paratypes)

Habitus. As shown in Fig. 1D-G.

MeAsurements. Total length: $2.10-2.47$, carapace $1.00-1.06$ long, $0.80-0.83$ wide.

Prosoma And opisthosoma. Coloration and other details of carapace, chelicera, and opisthosoma as in male. Head only slightly raised.

LEGS. Legs coloration, tibial spine formula, trichobothria and TmI as in male. Leg measurements as follows (based on one paratype): Leg I: 3.59 (1.02, 0.3, 0.95, 0.77, 0.55); Leg II: $3.36(0.95,0.28,0.87$, 0.75, 0.51); Leg III: 2.87 (0.81, 0.25, 0.71, 0.68, 0.42); Leg IV: $3.65(1.05,0.3,1.01,0.82,0.47)$.

Epigyne And vulva. As shown in Figs 2E-H, 3E-G. Lateral walls converging anteriorly. Anterior wall of epigyne with small projection. End of copulatory ducts with inflation, forming two small, transparent,

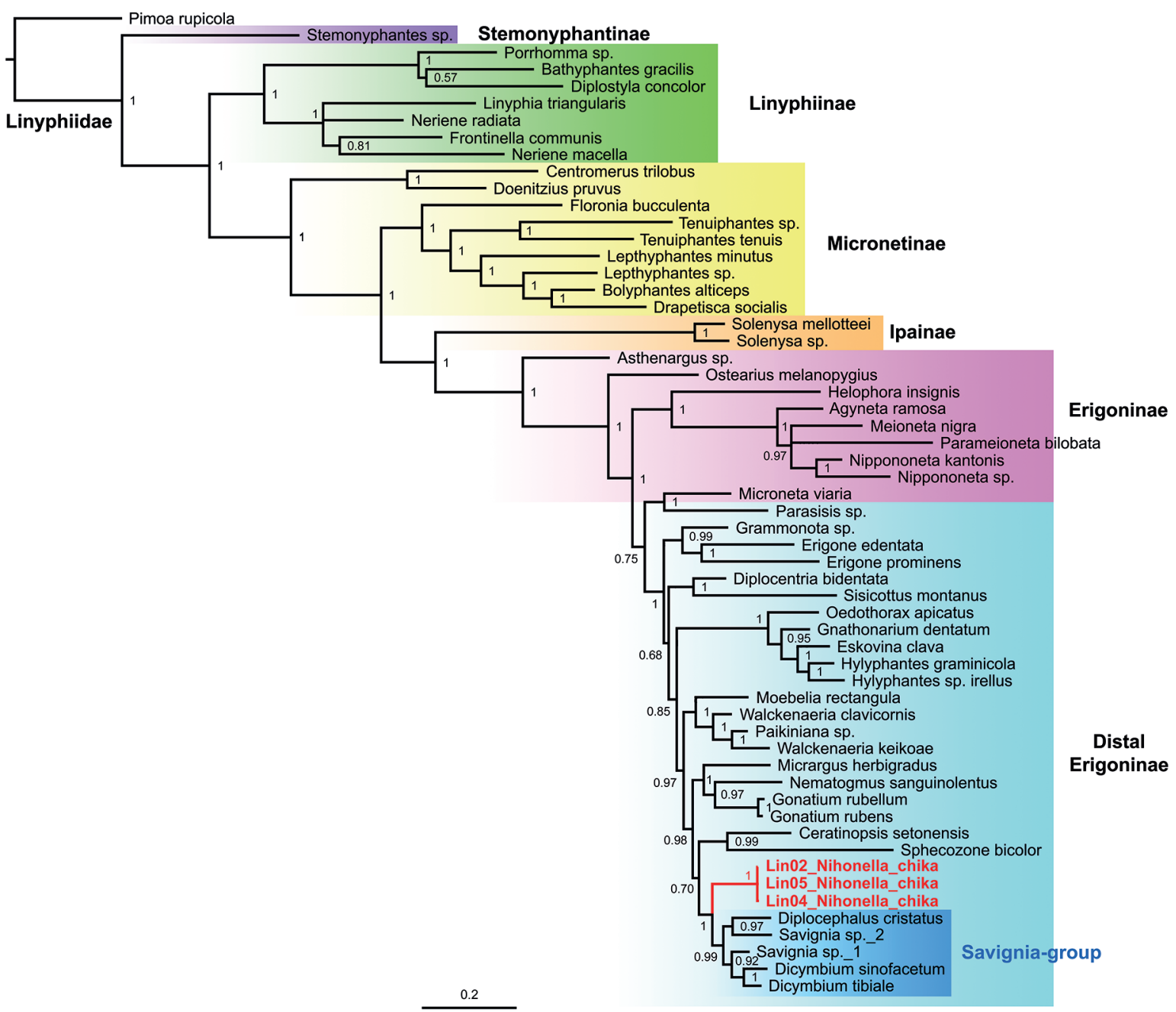

Fig. 5. Bayesian inference phylogenetic tree of Erigoninae and other subfamilies of Linyphiidae based on the five concatenated genes discussed in the text. Each color denotes a different subfamily while the Savignia group is indicated in blue. The phylogenetic position of the genus Nihonella gen. nov. is highlighted in red. Numbers at each node denote posterior probability support. Branch lengths are scaled in relation to the number of substitutions per site. 
ovoid plates in central part of the epigyne. Internal ducts visible through epigyne by transparency. Posterior medium plate larger than wide, approximately trapezoidal when epigyne is observed dorsally. Receptacles subspherical, located lateral to the PP. Copulatory ducts starting from posterior/inner side of receptacles, initial trait oriented towards posterior part of the epigyne, then turning frontally before reaching copulatory opening with twisted course. Copulatory openings located under ovoid plates, approximately at joining point of lateral walls.

\section{Ecology and habitat}

Although lacking extreme troglomorphic characters (e.g., eye loss), $N$. chika gen. et. sp. nov. shows troglophilic adaptations, such as body depigmentation. This species has only been found inside caves, several meters from the entrance, in the twilight and transition zones where the light is strongly reduced or absent. $N$. chika gen. et. sp. nov. builds small sheet-webs inside cracks or empty spaces between rocks on the cave floor.

\section{Distribution}

Endemic to Western Honshu, Japan. Currently known only for few caves in Okayama and Nara Prefectures (Fig. 6). Type locality: Anatoyama cave (穴門山洞窟) in Okayama Prefecture (Fig. 1H).

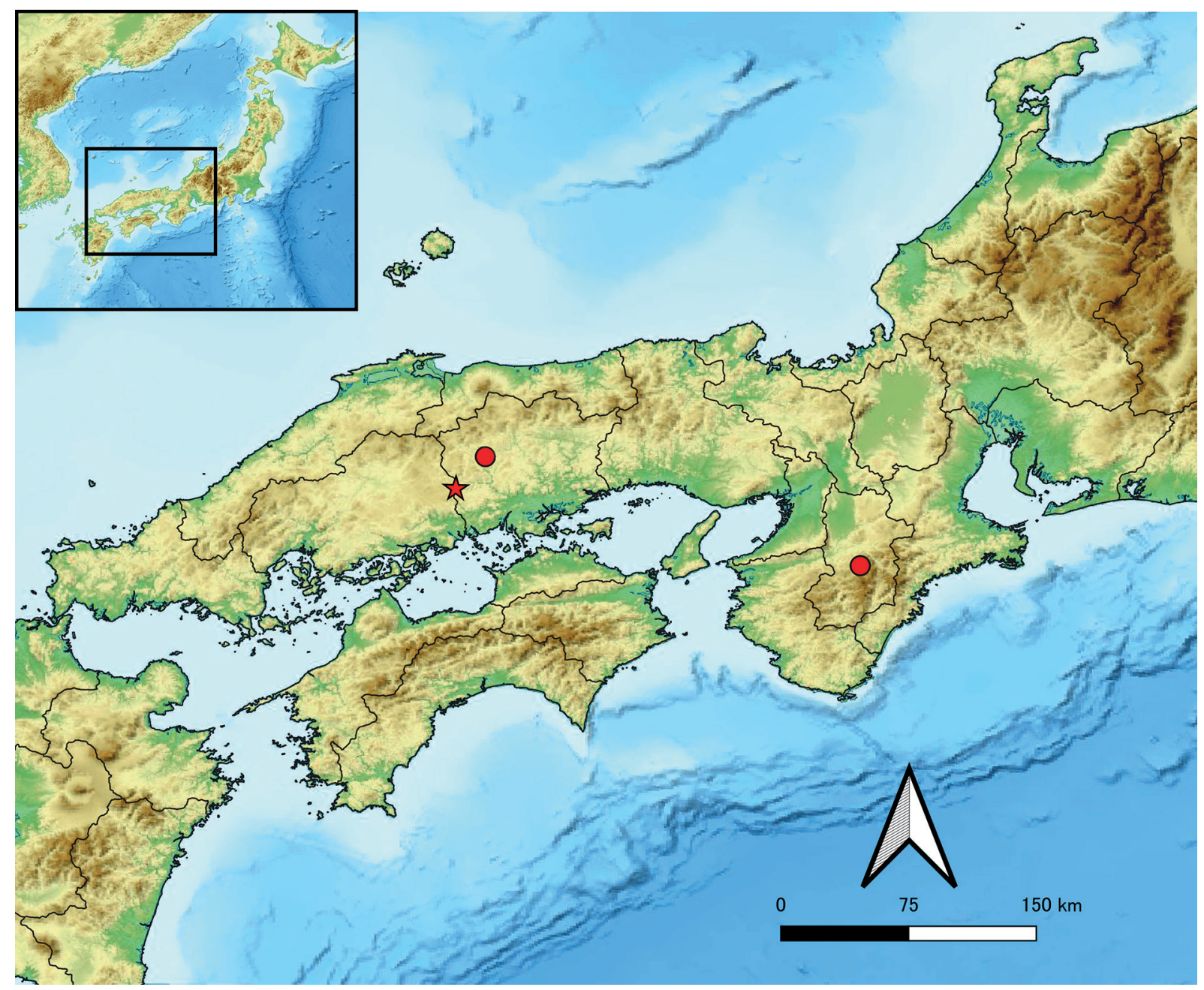

Fig. 6. Distribution of Nihonella chika gen. et. sp. nov. in Western Japan. The star refers to the type locality. 


\section{Molecular analysis}

The general structure of our Bayesian phylogeny (Fig. 5) shows strong similarity to phylogenies reported in previous studies on Linyphiidae (Miller \& Hormiga 2004; Arnedo et al. 2009; Zhao \& Li 2017). In our tree, the nodes of clades forming the main linyphiid subfamilies are strongly supported $(\mathrm{PP}=1)$ and show monophyly. Some genera of Micronetinae appear mixed together with the basal Erigoninae; this is in line with previous research and confirms that these two taxa, as they are currently recognized, are not monophyletic. Within the distal Erigoninae, the node support is sometimes low $(\mathrm{PP} \leq 0.85)$ and thus the phylogenetic positions of some genera are uncertain. Nevertheless, most of the main clades, including the Savignia group, are well-defined and with high node support $(\mathrm{PP}>0.95)$. In particular, the genera Dicymbium Menge, 1868, Diplocephalus Bertkau, 1883, and Savignia Blackwall, 1833 form a wellsupported clade, as hypothesised by Frick et al. (2014). Our analysis highly supports (PP=1) Nihonella gen. nov. as a distinct and well-defined genus within the subfamily Erigoninae, and in particular as part of the distal Erigoninae clade. Such results further suggest a close relationship between the new genus and the species forming the Savignia group sensu Millidge (1977).

The pairwise distance analysis (Table 2) shows a large genetic distance (13-15\%) between Nihonella gen. nov. and the Savignia group. Genera within the Savignia group are also separated to each other by between $10 \%$ and $19 \%$ genetic distance.

\section{Discussion}

Both the molecular results and the genital morphology support a close relationship of Nihonella gen. nov. with the main genera forming the Savignia group. Thus, we reject the hypothesis of morphological similarities in palp and epigyne between Nihonella gen. nov. and the Savignia group as the result of evolutionary convergence. Nevertheless, despite this affinity, well-defined genetic differences and distinctive traits in somatic characters and genital morphology clearly show that the new genus belongs to an independent monophyletic clade, separate from the Savignia group. In particular, a tibial spine formula of 1.1.1.1, as shown in the new genus, is unusual and in contrast with the standard chaetotaxy of the species forming the Savignia group. According to our phylogenetic results, Nihonella gen. nov. can be considered a sister clade to the Savignia group to which it shares a common ancestor.

The Savignia group remains an unresolved taxon, in need of further study. Although the wide majority of its species seem to share the same common origin, recent phylogenetic studies suggest that this group, as was originally defined by Millidge in 1977, is probably not monophyletic (Frick et al. 2010). Thus, more comprehensive analyses are necessary to evaluate the correct composition and systematic position of the Savignia group within the distal Erigoninae clade. Due to its probable close relationship and potential common ancestry with the Savignia group, Nihonella gen. nov. might be a promising genus to shed further light on the phylogeny of this group of species.

As far as we know, Linyphiidae are not commonly found in caves within Japan or other Asian countries (Zhao \& Li 2017). Some Japanese genera (e.g., Arcuphantes Chamberlin \& Ivie, 1943) inhabit the entrance and inner areas of natural large cavities, but their species are not endemic to the subterranean environment. Such limited affiliation with the hypogean habitat is also highlighted by the retention of cuticle pigmentation in these spiders. Among other linyphiid genera, in Japan only Porrhomma Simon, 1884 and Micrargus Dahl, 1886 seem to contain species which are only found in caves. Among endemic linyphiid cave species, only P. ohkawai Saito, 1977 and P. rakanum Yaginuma \& Saito, 1981 share marked troglobitic adaptations. No other obligate cave-dwelling linyphiid species were known in Japan until our research. With the present study, we add one more genus with clear troglophilic habits to the Japanese endemic fauna. Although Nihonella gen. nov. does not exhibit distinct troglobitic traits (e.g., 
eye loss), its depigmentation and preference for the inner traits of caves, as well as the lack of any known epigean record, suggest a strong affiliation with the subterranean environment.

Nihonella gen. nov. is currently monospecific, and has only been found in three localities. Nevertheless, the collection of specimens in caves in Okayama and Nara Prefectures, approximately $240 \mathrm{~km}$ away from each other, suggests that the new genus might be more widely distributed than currently known. Such lack of data is probably related to the scarcity of recent taxonomic studies on the Japanese cave spider fauna, with the last extensive surveys conducted in the 1970s. Further collections in Japanese caves, or other Asian karst areas, will probably lead to the discovery of new records of Nihonella chika gen. et. sp. nov. and, possibly, new congeners. The recent discovery of cave-adapted linyphiid genera in China (Zhao \& Li 2017), and now Japan, further indicates that the study of the troglophilic linyphiid fauna is in general still largely unexplored in East Asia. Specific taxonomic studies on these small spiders in Asian caves may lead to new and interesting discoveries.

\section{Acknowledgments}

We are particularly grateful to Andrei V. Tanasevitch (Russian Academy of Sciences, Russia) for his precious suggestions and advises on the taxonomy of Erigoninae, his help has been essential to correctly identify the new genus and define the diagnostic characters. We are equally grateful to Katsuyuki Eguchi and Noriaki Murakami (Tokyo Metropolitan University, Japan) for allowing us the use of microscopes and equipment for molecular analysis at TMU. Many thanks to Akio Tanikawa (University of Tokyo, Japan) for kindly helping with the field work in Nara Prefecture. We further thank Yamada Aiki (TMU, Japan) for his help on taking pictures with the SEM microscope. Victoria Smith (Canterbury Museum, New Zealand) kindly revised the English text of the manuscript. We are grateful to two anonymous referees who helped to improve the paper with their comments and suggestions. This work was supported by the YF 2018 and YF 2019 Japan Society for the Promotion of Science Postdoctoral Fellowships, Japan (JSPS KAKENHI n ${ }^{\circ} 18 \mathrm{~F} 18380$ and ${ }^{\circ} 19 \mathrm{~K} 16216$ ).

\section{References}

Arnedo M.A., Hormiga G. \& Scharff N. 2009. Higher level phylogenetics of linyphiid spiders (Araneae, Linyphiidae) based on morphological and molecular evidence. Cladistics 25 (3): 231-262. https://doi.org/10.1111/j.1096-0031.2009.00249.x

Balczun C., Bunse A., Hahn D., Bennoun P., Nickelsen J. \& Kück U. 2005. Two adjacent nuclear genes are required for functional complementation of a chloroplast trans-splicing mutant from Chlamydomonas reinhardtii. The Plant Journal 43: 636-648. https://doi.org/bmhq4z

Bosmans R. 2007. Contribution to the knowledge of the Linyphiidae of the Maghreb. Part XII. Miscellaneous erigonine genera and additional records (Araneae: Linyphiidae: Erigoninae). Bulletin \& Annales de la Société entomologique de Belgique 143: 117-163.

Fernandez R., Kallal R.J., Dimitrov D., Ballesteros J.A., Arnedo M.A., Giribet G. \& Hormiga G. 2018. Phylogenomics, diversification dynamics, and comparative transcriptomics across the spider tree of life. Current Biology 28 (9): 1489-1497. https://doi.org/10.1016/j.cub.2018.03.064

Frick H., Nentwig W. \& Kropf C. 2010. Progress in Erigonine spider phylogeny - the Savignia-group is not monophyletic (Araneae: Linyphiidae). Organisms Diversity \& Evolution 10 (4): 297-310. https://doi.org/10.1007/s13127-010-0023-1

Giribet G., Carranza S., Baguñà J., Riutort M. \& Ribera C. 1996. First molecular evidence for the existence of a Tardigrada + Arthropoda clade. Molecular Biology and Evolution 13: 76-84.

https://doi.org/fp2w 
Hall T.A. 1999. Bioedit: a user-friendly biological sequence alignment editor and analysis program for Windows 95/98/NT. Nucleic Acids Symposium Series 41: 95-98.

Katoh K., Rozewicki J. \& Yamada K.D. 2019. MAFFT online service: multiple sequence alignment, interactive sequence choice and visualization. Briefings in Bioinformatics 20: 1160-1166. Available from https://mafft.cbrc.jp/alignment/software [accessed 5 Jan. 2021].

https://doi.org/10.1093/bib/bbx108

Kumar S., Stecher G., Li M., Knyaz C. \& Tamura K. 2018. MEGA X: molecular evolutionary genetics analysis across computing platforms. Molecular Biology and Evolution 35 (6): 1547-1549.

https://doi.org/10.1093/molbev/msy096

Lanfear R., Frandsen P.B., Wright A.M., Senfeld T. \& Calcott B. 2017. PartitionFinder 2: new methods for selecting partitioned models of evolution for molecular and morphological phylogenetic analyses. Molecular Biology and Evolution 34 (3): 772-773. https://doi.org/10.1093/molbev/msw260

Miller M.A., Pfeiffer W. \& Schwartz T. 2010. Creating the CIPRES Science Gateway for inference of large phylogenetic trees. Proceedings of the Gateway Computing Environments Workshop (GCE), 14 Nov. 2010, New Orleans: 1-8. Available from https://www.phylo.org/ [accessed 6 Jan. 2021]. https://doi.org/10.1109/GCE.2010.5676129

Miller J.A. \& Hormiga G. 2004. Clade stability and the addition of data: a case study from erigonine spiders (Araneae: Linyphiidae, Erigoninae). Cladistics 20 (5): 385-442.

https://doi.org/10.1111/j.1096-0031.2004.00033.x

Millidge A.F. 1977. The conformation of the male palpal organs of linyphiid spiders, and its application to the taxonomic and phylogenetic analysis of the family (Araneae: Linyphiidae). Bulletin of the British arachnological Society 4 (1): 1-60.

Ono H., Matsuda M. \& Saito H. 2009. Linyphiidae, Pimoidae. In: Ono H. (ed.) The Spiders of Japan with Keys to the Families and Genera and Illustrations of the Species. Tokai University Press, Kanagawa.

Rambaut A., Drummond A.J., Xie D., Baele G. \& Suchard M.A. 2018. Posterior summarization in Bayesian phylogenetics using Tracer 1.7. Systematic Biology 67 (5): 901-904.

https://oi.org/10.1093/sysbio/syy032

Ronquist F., Teslenko M., Van Der Mark P., Ayres D.L., Darling A., Höhna S. \& Huelsenbeck J.P. 2012. MrBayes 3.2: efficient Bayesian phylogenetic inference and model choice across a large model space. Systematic Biology 61 (3): 539-542. https://doi.org/10.1093/sysbio/sys029

Tanasevitch A.V. 2020. Linyphiid Spiders of the World.

Available from http://old.cepl.rssi.ru/bio/tan/linyphiidae/ [accessed 25 Jul. 2020].

Tanikawa A. 2020. A Check List of Japanese Spiders ver. 2020 R1.

Available from http://www.asahi-net.or.jp/ dp7a-tnkw/japan.pdf [accessed 25 Jul. 2020].

Wheeler W.C., Coddington J.A., Crowley L.M., Dimitrov D., Goloboff P.A., Griswold C.E., Hormiga G., Prendini L., Ramírez M.J., Sierwald P., Almeida-Silva L., Alvarez-Padilla F., Arnedo M.A., Silva L.R.B., Benjamin S.P., Bond J.E., Grismado C.J., Hasan E., Hedin M., Izquierdo M.A., Labarque F.M., Ledford J., Lopardo L., Maddison W.P., Miller J.A., Piacentini L.N., Platnick N.I., Polotow D., SilvaDávila D., Scharff N., Szüts T., Ubick D., Vink C.J., Wood H.M. \& Zhang J. 2017. The spider tree of life: phylogeny of Araneae based on target-gene analyses from an extensive taxon sampling. Cladistics 33 (6): 574-616. https://doi.org/10.1111/cla.12182

World Spider Catalog (2020) World Spider Catalog. Version 21.5. Natural History Museum Bern. Available from http://wsc.nmbe.ch [accessed 6 Jan. 2021]. https://doi.org/10.24436/2 
Zhao Q. \& Li S. 2017. Callosa gen. n., a new troglobitic genus from southwest China (Araneae, Linyphiidae). ZooKeys 703: 109-128. https://doi.org/10.3897/zookeys.703.13641

Manuscript received: 4 September 2020

Manuscript accepted: 10 November 2020

Published on: 26 January 2021

Topic editor: Rudy Jocqué

Desk editor: Eva-Maria Levermann

Printed versions of all papers are also deposited in the libraries of the institutes that are members of the EJT consortium: Muséum national d'histoire naturelle, Paris, France; Meise Botanic Garden, Belgium; Royal Museum for Central Africa, Tervuren, Belgium; Royal Belgian Institute of Natural Sciences, Brussels, Belgium; Natural History Museum of Denmark, Copenhagen, Denmark; Naturalis Biodiversity Center, Leiden, the Netherlands; Museo Nacional de Ciencias Naturales-CSIC, Madrid, Spain; Real Jardín Botánico de Madrid CSIC, Spain; Zoological Research Museum Alexander Koenig, Bonn, Germany; National Museum, Prague, Czech Republic. 